\title{
Subchannel Analysis of Wire Wrapped SCWR Assembly
}

\author{
Jianqiang Shan, Henan Wang, Wei Liu, Linxing Song, Xuanxiang Chen, and Yang Jiang
}

Xian Jiaotong University, Xian, Shannxi 710049, China

Correspondence should be addressed to Jianqiang Shan; jqshan@mail.xjtu.edu.cn

Received 10 October 2013; Accepted 13 January 2014; Published 23 February 2014

Academic Editor: Liangzhi Cao

Copyright (C) 2014 Jianqiang Shan et al. This is an open access article distributed under the Creative Commons Attribution License, which permits unrestricted use, distribution, and reproduction in any medium, provided the original work is properly cited.

\begin{abstract}
Application of wire wrap spacers in SCWR can reduce pressure drop and obtain better mixing capability. As a consequence, the required coolant pumping power is decreased and the coolant temperature profile inside the fuel bundle is flattened which will obviously decrease the peak cladding temperature. The distributed resistance model for wire wrap was developed and implemented in ATHAS subchannel analysis code. The HPLWR wire wrapped assembly was analyzed. The results show that: (1) the assembly with wire wrap can obtain a more uniform coolant temperature profile than the grid spaced assembly, which will result in a lower peak cladding temperature; (2) the pressure drop in a wire wrapped assembly is less than that in a grid spaced assembly, which can reduce the operating power of pump effectively; (3) the wire wrap pitch has significant effect on the flow in the assembly. Smaller $H_{\text {wire }} / D_{\text {rod }}$ will result in stronger cross flow a more uniform coolant temperature profile, and also a higher pressure drop.
\end{abstract}

\section{Introduction}

The supercritical water-cooled reactor (SCWR) is essentially a water reactor operating above the thermodynamic critical point of water $(\mathrm{Pc}=22.064 \mathrm{MPa})$. It is considered as one of the most promising Generation IV reactors because of its simplicity, high thermal efficiency, and nearly fifty years of industrial experience from thermal-power stations with a SCW cycle [1]. Evolving from the existing designs, there are currently two types of SCWR concepts [2]: (a) a large reactor pressure vessel containing the reactor core (fuelled) heat source, analogous to conventional PWRs and BWRs, and (b) distributed pressure tubes or channels containing fuel bundles, analogous to conventional CANDU and RBMK nuclear reactors. The arrangement of separated moderator (moderator box in pressure vessel type and heavy water moderator in calandria in pressure tube type) is applied in each design, due to the sharp change in the thermal properties of coolant near the pseudo-critical point.

To obtain a small water volume fraction in core, tight lattices are necessary. Wire wrap spacers, an alternative to grid spacers, have been used extensively in LMFBR [3] and tight-lattice high-conversion cores [4], mainly due to their advantageous pressure drop and better mixing capability. As a consequence, the required coolant pumping power is decreased and the coolant temperature profile inside the fuel bundle is flattened which will obviously decrease the peak cladding temperature. The other potential advantage of wire wrap spacer is that it can improve the heat transfer at the rod gap where heat transfer deterioration occurs in SCWR assembly. For SCWR design, wire wrapped assembly has been selected in both three-pass HPLWR [5] and US SCWR [6].

The influence of wire wrap under supercritical pressure conditions should be well studied. Himmel et al. [7] studied the mixing coefficients for a subchannel flow through a HPLWR fuel assembly with 40 wire wrapped fuel pins in a square arrangement, and their analyses were concentrated on a section of 3 subchannels between the assembly box and the inner moderator box walls. Laurien et al. [8] carried out the heat transfer experiments with a $10 \mathrm{~mm}$ rod inside a square vertical channel with a wire wrapped helically around it. The results showed that, based on the comparison with an identical channel without the helical wrapped wire, the wire spacer did not enhance the heat transfer significantly under normal heat transfer conditions but helped improve the heat transfer in the pseudo-critical region and shift the onset of the deterioration to downstream. Chandra et al. [9] analyzed the wire wrap effect with CFD method. The results showed that the adiabatic helical wire wrap around the inner heated cylinder of the annulus prevented the heat transfer 
deterioration from occurring in the considered test case, even at very high heat fluxes. This was related to the enhanced production of the turbulent kinetic energy by the presence of helical wire wrap, which increased the turbulent mixing effect and consequently the heat transfer and finally reduced the wall temperature.

To better understand the behavior of the coolant and cladding under the influence of wire wrap in the whole assembly, subchannel analysis is an effective and simpler method. The present paper developed a subchannel code for wire wrapped SCWR bundle based on the ATHAS code.

\section{Model Description}

2.1. Basic Conservation Equations of ATHAS. The basic equations of the mathematical model [10] are derived by applying the general equations of continuity, energy, and momentum to a subchannel $i$ control volume $j$. The equations are as follows.

Mass. Consider

$$
\bar{A} \frac{\partial}{\partial t}\langle\langle\rho\rangle\rangle_{V}+\frac{\partial}{\partial Z}\left(\langle\rho u\rangle_{A} A\right)+\sum_{k=1}^{n_{k}}\left(\left\langle\rho V_{k}\right\rangle_{s} S\right)_{k}=0
$$

where the density, the axial mass flux, and the lateral mass flux are defined by

$$
\begin{gathered}
\langle\langle\rho\rangle\rangle_{V}=\frac{1}{V} \int_{V} \rho d V, \quad\langle\rho u\rangle_{A}=\frac{1}{A} \int_{A} \rho u d A, \\
\langle\rho v\rangle_{A}=\frac{1}{A} \int_{A} \rho v d A .
\end{gathered}
$$

The first term is the time rate of change of mass per unit axial length and the second is spatial variation in axial mass flux per unit length. The last term is the sum on all gap connections of the lateral mass flux per unit length which is the cross flow associated with subchannel analysis.

Energy. Consider

$$
\begin{aligned}
\bar{A} \frac{\partial}{\partial t}\langle\langle\rho h\rangle\rangle_{V}+\frac{\partial}{\partial Z}\langle\rho h u\rangle_{A} A+\sum_{k=1}^{n_{k}}\left[\left\langle\rho h V_{k}\right\rangle_{S} S\right]_{k} \\
=\sum_{r=1}^{n_{r}}\left[P_{r} \Phi_{j} H_{r}\left(t_{r}-t_{f}\right)\right]_{r}+\sum_{W=1}^{n_{W}}\left[L_{W} H_{W}\left(t_{W}-t_{f}\right)\right]_{W} \\
+\frac{\partial}{\partial Z} A\left\langle k_{f} \frac{\partial t}{\partial Z}\right\rangle_{A}-\sum_{k=1}^{n_{k}}\left[\frac{S \cdot C_{g} k_{f}}{L_{c}}\left(t_{i}-t_{j}\right)\right]_{k} \\
-\sum_{k=1}^{n_{k}}\left[W^{\prime\left(h_{i}^{\prime}-h_{j}^{\prime}\right)}\right]_{k} .
\end{aligned}
$$

The equation considers the heat transfer from the rod and wall-to-channel (if necessary) to the control volume, the axial fluid heat conduction, the lateral fluid heat conduction through the gap between two channels, and turbulent energy input.

Axial Momentum. Consider

$$
\begin{aligned}
\bar{A} & \frac{\partial}{\partial t}\langle\langle\rho u\rangle\rangle_{V}+\frac{\partial}{\partial Z}\left\langle\rho u^{2}\right\rangle_{A} A+\sum_{k=1}^{n_{k}}\left[\left\langle\rho V_{k} u\right\rangle_{S} S\right]_{k} \\
= & -\bar{A} \frac{\partial}{\partial Z}\langle p\rangle_{A}-\frac{1}{2}\left(\frac{f}{D_{e}}+\frac{C}{\Delta Z}\right)\left\langle\rho u^{2}\right\rangle_{A} A \\
& -g \bar{A}\langle\langle\rho\rangle\rangle_{V} \cos \theta-C_{T} \sum_{k=1}^{n_{k}}\left[W^{\prime}\left(u_{t}^{\prime}-u_{f}^{\prime}\right)\right]_{k} .
\end{aligned}
$$

The first term at the left side is the time rate of change of momentum per unit axial length and the second and third are the spatial variation in axial momentum per unit length. The four terms at right side are the total pressure force on the control volume, axial drag force, the gravity force, and the force due to turbulent mixing, respectively.

Lateral Momentum. Consider

$$
\begin{aligned}
C_{S}\left\{\sum_{k=1}^{n_{k}}\left[\left\langle\rho V_{k}\right\rangle_{S} \frac{S}{l} \cos \Delta \beta\right]_{k, j}-\sum_{k=1}^{n_{k}}\left[\left\langle\rho V_{k}\right\rangle_{S} \frac{S}{l} \cos \Delta \beta\right]_{k, i}\right\} \\
\quad+\frac{\partial}{\partial t}\left\langle\left\langle\rho V_{k}\right\rangle\right\rangle_{V^{\prime}} S+\frac{\partial}{\partial Z}\left\langle\rho u V_{k}\right\rangle_{A^{\prime}} S \\
=\frac{b}{l}\left(\langle p\rangle_{A, i}-\langle p\rangle_{A, j}\right)-\frac{1}{2} \frac{S}{l} k_{G}\left\langle\rho V_{k}^{2}\right\rangle_{S} \\
\quad-g\langle\langle\rho\rangle\rangle_{V^{\prime}} S \sin \theta \cos \beta .
\end{aligned}
$$

The first term at the left side is the net lateral momentum flux and the factor $C_{s}$ is included to help account for the imperfect coupling between communicating gaps. The second and third terms at the left side are the time rate of change of lateral momentum per unit lateral length and spatial variation in lateral momentum per unit length. The three terms at the right side are the pressure difference between adjacent channels, the total drag force, and the gravity force, respectively.

The constitutive correlations selected in the analysis are shown as follows based on Shan et al.'s work [10].

Friction coefficient: Blasius correlation [11] for single phase turbulent flow:

$$
f=0.3164 \operatorname{Re}^{-0.25} .
$$

Heat transfer coefficient: Bishop correlation (1964) [12] for supercritical water:

$$
N u_{x}=0.0069 \operatorname{Re}_{x}^{0.9} \overline{\operatorname{Pr}}_{x}^{0.66}\left(\frac{\rho_{w}}{\rho_{b}}\right)_{x}^{0.43}\left(1+2.4 \frac{D}{x}\right) .
$$

Turbulent mixing factor: Rowe and Angle correlation [13] in the bundle condition:

$$
\beta=0.021 \cdot \operatorname{Re}^{-0.1} \text {. }
$$


The selection of Blasius correlation, Bishop correlation (1964), and Rowe and Angle correlation in this paper can obtain relatively high maximum cladding surface temperature and present more conservative estimate.

The code has been validated under supercritical pressure condition [14] and successfully applied in the analysis of pressure vessel and pressure tube type SCWR bundle $[10,15$, $16]$.

2.2. Wire Wrap Model. Hydraulic resistance model which was initially proposed by Ninokata et al. [17] is developed to account for the existence of the wire wrap spacer in rod bundle. These models are of "distributed resistance" type and add flow resistance term into the axial and transverse momentum equations as a function of subchannel geometry and flow velocity. The models are general enough to cover a wide range of geometrical parameters, wire position, and flow regime.

In the subchannel formulation, it is a common practice to assume three types of control volume for (1) mass and energy balance, (2) lateral momentum balance, and (3) axial momentum balance. Figure 1 illustrates the typical mass and energy balance control volume (ABCDEF-LMNJPQ) and lateral momentum control volume (SPTUKV-GYZWOX). Note that the control volume for the axial momentum balance is staggered in the axial direction with respect to the energy and mass balance control volume.

In this study, focus is mainly placed on the momentum balance conservation equation, that is, (4) and (5). The second terms at the right side of (4) and (5) represent the momentum exchange between the solid surface and the fluid. These terms, which are the forces exerted on the fluid by the wall, are replaced with the distributed resistance terms. These terms for the rod bundles with wire wraps can be divided into four components, as shown in Figure 2. These forces of $F_{R}^{L}$ and $F_{W}^{N}$ are estimated by correlations depending on the direction of the dominant flow. Each force can be written as

$$
\begin{gathered}
F_{R}^{A}=R(c)\left(\frac{A_{R}}{A_{w}^{\prime \prime}}\right) \cos \alpha, \\
F_{W}^{T}=R(c)\left(1-\frac{A_{R}}{A_{W}^{\prime \prime}}\right) \cos (\varphi-\alpha),
\end{gathered}
$$

where

$$
\begin{gathered}
R(c)=\frac{A_{W}^{\prime \prime} f_{M}(c)}{8} \rho c|c| \\
c^{2}=u^{2}+v^{2} .
\end{gathered}
$$

For the predominantly axial flow,

$$
\begin{gathered}
F_{R}^{L}=\frac{A_{W}^{\prime \prime} f_{G}}{8} \rho|v| v\left(\frac{D_{V}^{\prime \prime}}{S_{T}}\right)^{0.4}\left(\frac{S_{L}}{S_{T}}\right)^{0.6}, \\
F_{W}^{N}=\frac{A_{W P} f_{n}}{2} \rho\left|v_{k}\right| v_{k}
\end{gathered}
$$

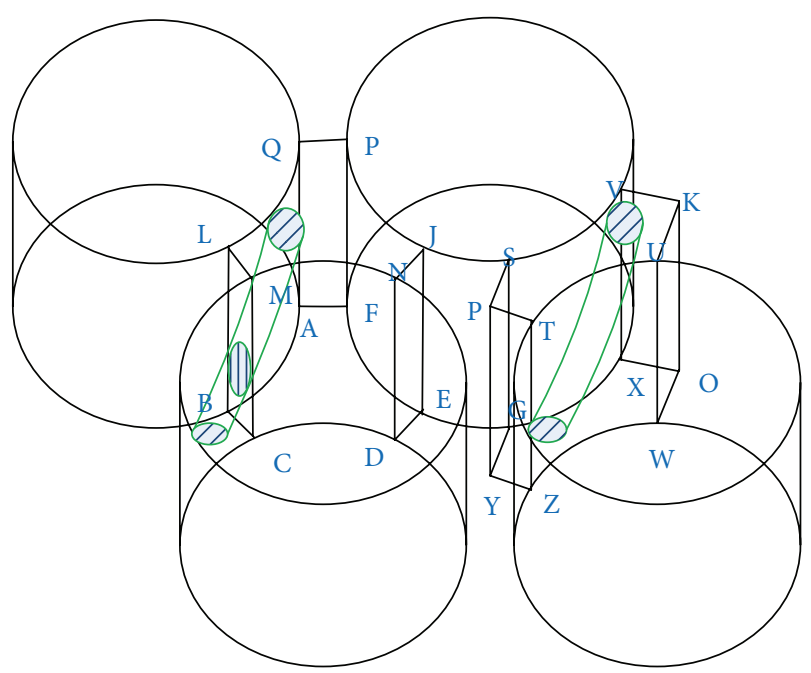

FIGURE 1: Three-dimensional view of a subchannel and a gap with wire wrap.

where $f_{G}$ is a friction factor based on the cross flow Reynolds number, $S_{T}$ is the rod pitch, and $S_{L}$ is the distance between two rods in a transverse row (Figure 3 ).

The hydraulic resistance per unit volume for the solution of the axial and lateral momentum equations, respectively, can be represented as follows:

$$
\begin{gathered}
\frac{1}{2}\left(\frac{f}{D_{e}}+\frac{C}{\Delta Z}\right)\left\langle\rho u^{2}\right\rangle_{A} A=F_{R}^{A}+F_{W}^{T} \cos \varphi+F_{W}^{N} \sin \varphi, \\
\frac{1}{2} \frac{S}{l} k_{G}\left\langle\rho V_{k}^{2}\right\rangle_{S}=F_{R}^{L}+F_{W}^{T} \sin \varphi-F_{W}^{N} \cos \varphi .
\end{gathered}
$$

\section{Results and Analysis}

3.1. Description of HPLWR Assembly. The high performance light water reactor (HPLWR) is funded by the European Commission. A specific core design proposed by Schulenberg et al. [18] assumes that the coolant is guided three times through the core during its heat-up from $280^{\circ} \mathrm{C}$ to $500^{\circ} \mathrm{C}$ at a system pressure of $25 \mathrm{MPa}$. Figure 4 illustrates the HPLWR assembly configuration. Fischer et al. [5] gave the detailed design as follows: the assembly cluster is built with nine assemblies and with a gap of $10 \mathrm{~mm}$ between the boxes; a total number of 40 fuel rods per assembly with $8 \mathrm{~mm}$ outer cladding diameter at a pitch of $9.44 \mathrm{~mm}$ are housed within a stainless steel box of $2.5 \mathrm{~mm}$ wall thickness and $72.5 \mathrm{~mm}$ outer size; a single wire of $1.34 \mathrm{~mm}$ diameter is wrapped around each fuel rod with an axial pitch of $200 \mathrm{~mm}$, leaving a tolerance of $0.1 \mathrm{~mm}$ between the wire and the fuel rods or the box walls, respectively; the inner moderator box has an outer size of $26.9 \mathrm{~mm}$ and a wall thickness of $0.8 \mathrm{~mm}$, which is made from stainless steel as well; the active core height is assumed to be $4.2 \mathrm{~m}$ and the total length of the fuel rods is considered as $4.71 \mathrm{~m}$ if the fission gas plenum is included. Figure 4 shows the subchannel and fuel identification in a HPLWR fuel bundle. Totally 60 subchannels, 40 rods, 


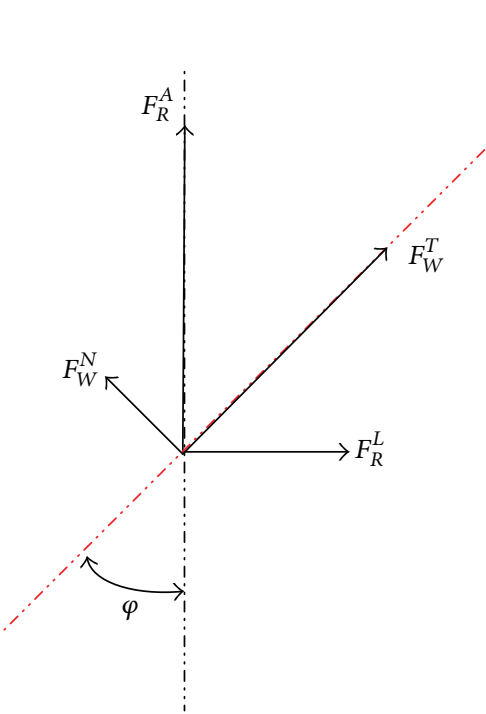

(a)

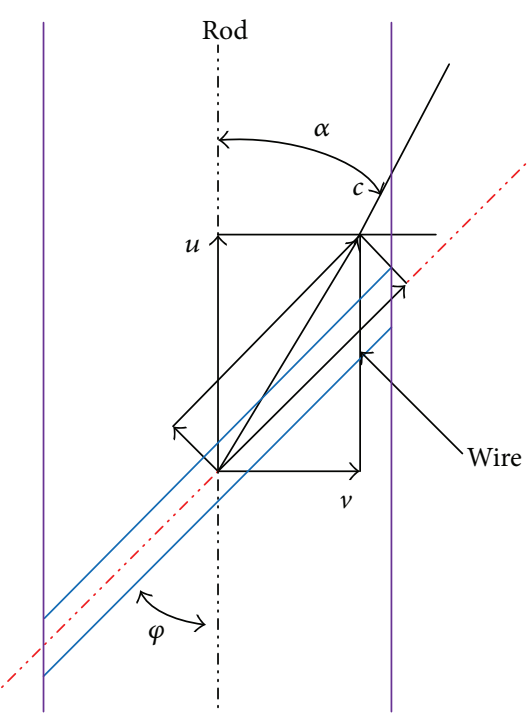

(b)

FIgURE 2: Component of the drag forces and velocities in a wire wrapped rod.

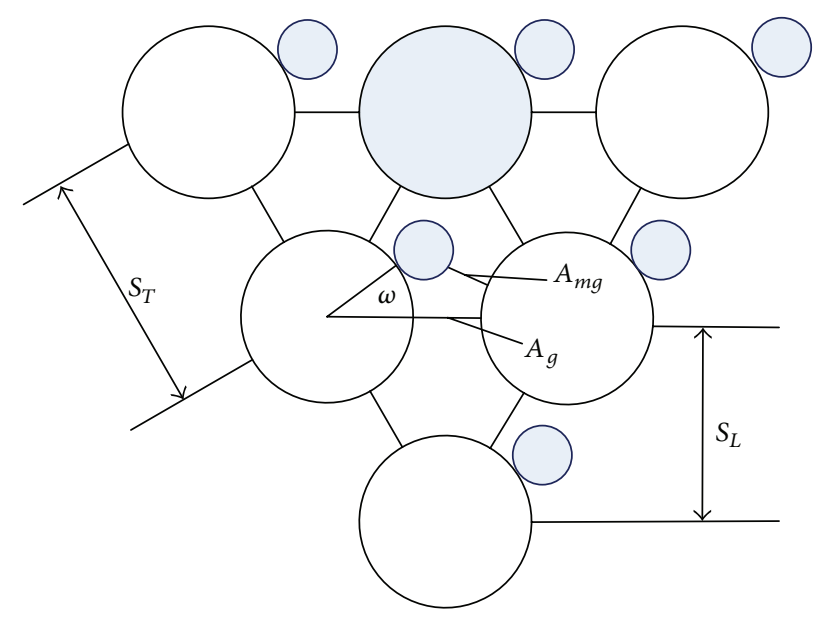

FIGURE 3: Average wire wrap position and gap definition.

and 2 conducting walls are defined here. The heat transfer between the subchannels and moderator box/assembly gap is also considered with conducting wall model in the ATHAS code.

Table 1 lists the geometry of the assembly and Table 2 gives the operating parameters. Figure 5 shows the relative axial power distribution, which is the result of neutronic/thermal-hydraulics coupling analysis [19]. The radial power distribution is assumed as uniform.

3.2. Subchannel Analysis Results with Wire Wrapped and Grid Spaced Assemblies. To compare with the behavior of wire wrap in the SCWR assembly, a subchannel analysis of assembly with grid space is also taken. The parameters of grid

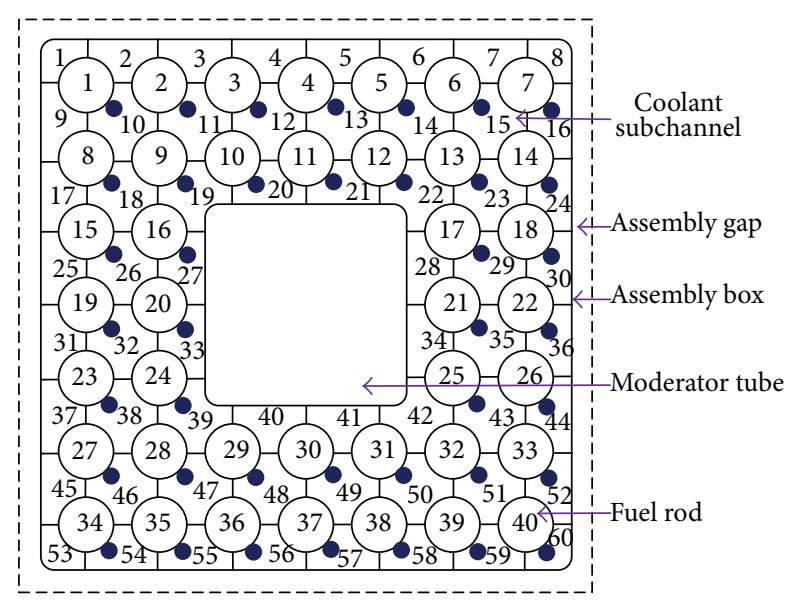

FIgUre 4: Fuel assembly design and subchannel identification.

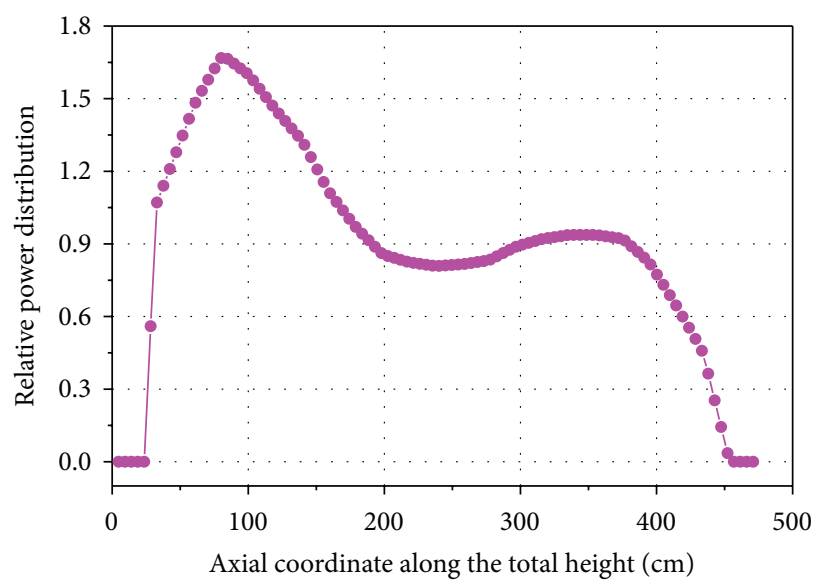

FIGURE 5: Relative power distribution. 


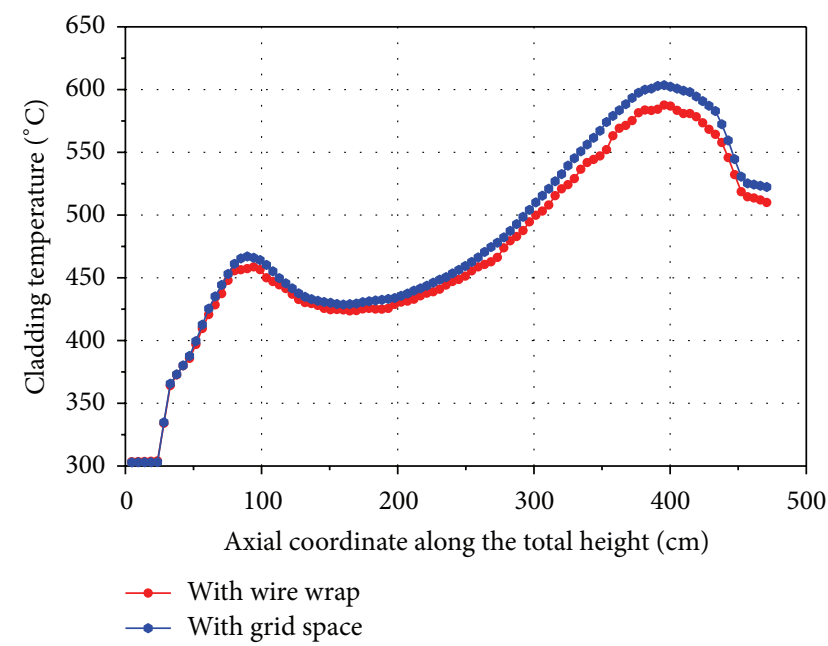

Figure 6: Axial cladding temperature profile in the hot channel.

TABLE 1: Fuel assembly geometry parameters.

\begin{tabular}{lc}
\hline Parameters & Values \\
\hline Fuel rod outer diameter & $8.00 \mathrm{~mm}$ \\
Fuel rod pitch & $9.44 \mathrm{~mm}$ \\
Pitch/diameter ratio $(P / D)$ & 1.18 \\
Active height & $4200 \mathrm{~cm}$ \\
Total height & $4710 \mathrm{~cm}$ \\
Wire diameter & $1.34 \mathrm{~mm}$ \\
Wire pitch & $200 \mathrm{~mm}$ \\
Moderator box length & $26.9 \mathrm{~mm}$ \\
Moderator box wall thickness & $0.8 \mathrm{~mm}$ \\
Outside box length & $72.5 \mathrm{~mm}$ \\
Outside box wall thickness & $2.5 \mathrm{~mm}$ \\
Gap between fuel rod and box wall & $1.43 \mathrm{~mm}$ \\
0.5 gap around one fuel assembly & $5.0 \mathrm{~mm}$ \\
\hline
\end{tabular}

spacers are given by Cheng et al. [20]. There are 15 grid spacers along the axial lengths.

The comparison of axial cladding temperature profiles in the hot channel between wire wrapped and grid spaced assemblies is shown in Figure 6. The peak cladding temperature is $587.6^{\circ} \mathrm{C}$ for wire wrapped assembly and $603.5^{\circ} \mathrm{C}$ for grid spaced assembly, respectively. The location of peak cladding temperature is at subchannel 43 , rod 25 , and $3.96 \mathrm{~m}$ at axial position. The reason for the temperature difference is that more forced cross flow between subchannels, result in a more uniform coolant temperature profile. Figure 7 shows the coolant temperature profile in the subchannels at the axial position where the peak cladding temperature occurs. The difference of coolant temperature between the hottest and coldest channels is $25.3^{\circ} \mathrm{C}$ for the wire wrap and $40.2 \circ \mathrm{C}$ for the grid spacer, respectively. Figure 8 shows the pressure drop in the two kinds of assembly; it can be observed that the pressure loss in the wire wrapped assembly is less than that in the grid spaced assembly, which consequently can reduce the required pump power.
TABLE 2: Reactor operation parameters and correlations options in current analysis.

\begin{tabular}{lc}
\hline Parameters & Values \\
\hline Coolant inlet pressure & $25 \mathrm{MPa}$ \\
Coolant inlet temperature & $280^{\circ} \mathrm{C}$ \\
Coolant exit temperature & $500^{\circ} \mathrm{C}$ \\
Average heat flux & $0.6142 \mathrm{MW} \cdot \mathrm{m}^{-2}$ \\
Mass flux & $780 \mathrm{~kg} \cdot \mathrm{m}^{-2} \cdot \mathrm{s}^{-1}$ \\
\hline
\end{tabular}

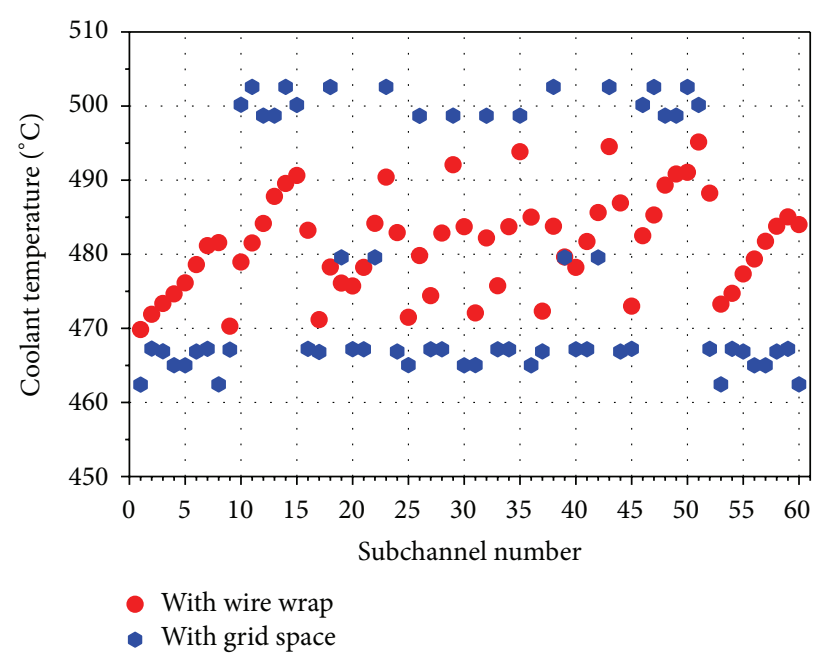

FIGURE 7: Coolant temperature profile at axial position where the peak cladding temperature occurs.

3.3. Sensitivity Analysis of Wire Wrap Pitch. Sensitivity analysis of wire wrap pitch was also studied. The pitch is selected according to the criteria determined by Diller [21], $H_{\text {wire }} / D_{\text {rod }}<50$. So four $H_{\text {wire }} / D_{\text {rod }}$ values have been selected for analysis, which are $H_{\text {wire }} / D_{\text {rod }}=20,30,40$, and 50, respectively.

Figure 9 shows the comparison of exit cooling temperature profiles with different $H_{\text {wire }} / D_{\text {rod }}$ values. It is found that lower $H_{\text {wire }} / D_{\text {rod }}$ will result in a more uniform profile, since the temperature difference between the hottest and coldest channels is $60.9^{\circ} \mathrm{C}$ for $H_{\text {wire }} / D_{\text {rod }}=50$ and $21.9^{\circ} \mathrm{C}$ for $H_{\text {wire }} / D_{\text {rod }}=20$. This is understandable because lower $H_{\text {wire }} / D_{\text {rod }}$ causes more cross flow. However, lower $H_{\text {wire }} / D_{\text {rod }}$ also leads to a higher pressure drop, as shown in Figure 10. The pressure drop is increased from $51.8 \mathrm{kPa}$ for $H_{\text {wire }} / D_{\text {rod }}=$ 50 to $56.1 \mathrm{kPa}$ for $H_{\text {wire }} / D_{\text {rod }}=20$.

Figure 11 shows the peak cladding temperature comparison with different $H_{\text {wire }} / D_{\text {rod }}$ values. As we have discussed before, the peak cladding temperature mainly depends on whether the coolant temperature profile in subchannels is uniform or not. Higher $H_{\text {wire }} / D_{\text {rod }}$ will result in a higher cladding temperature. As for $H_{\text {wire }} / D_{\text {rod }}=50$, the calculated peak cladding temperature is $603.3^{\circ} \mathrm{C}$, nearly the same as grid spaced assembly. 


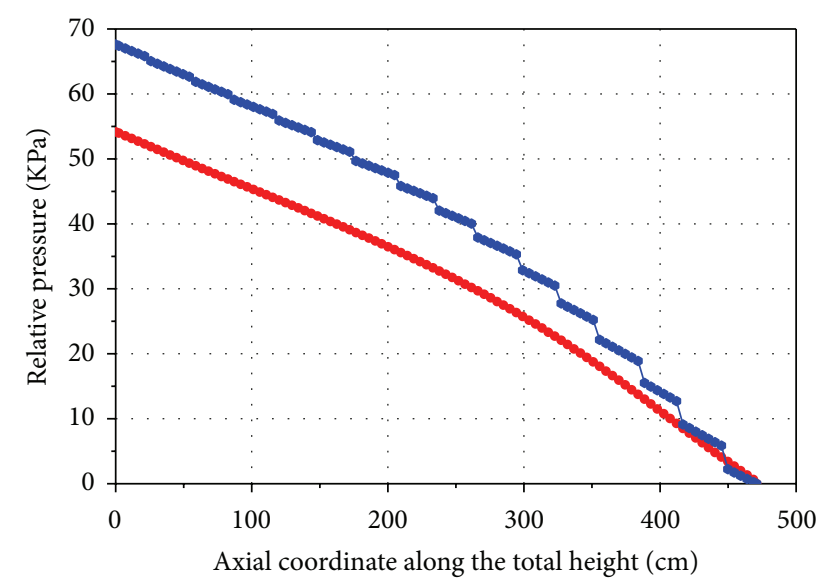

- With wire wrap

$\rightarrow$ With grid space

FIGURE 8: Pressure drop of two kinds of assembly.

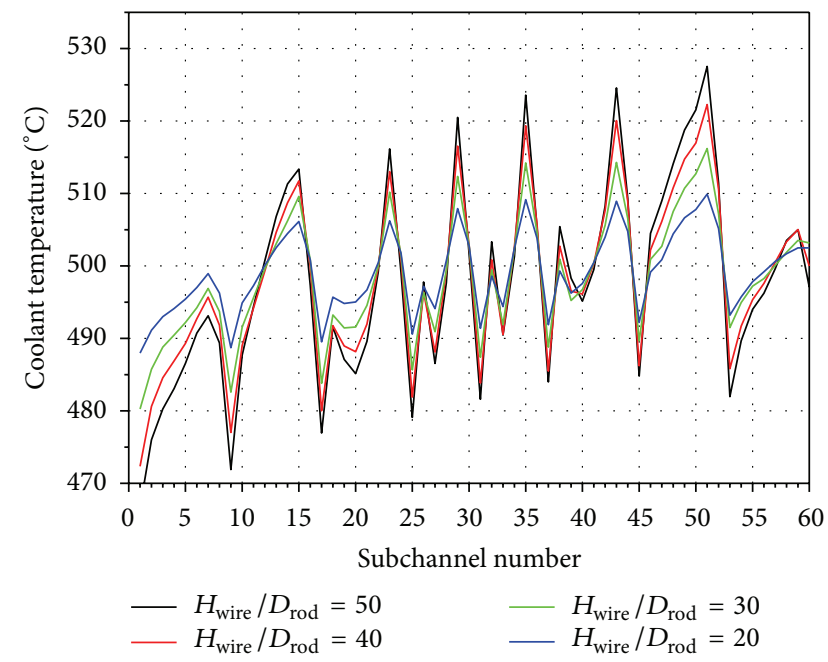

FIGURE 9: Exit cooling temperature profile with different $H_{\text {wire }} / D_{\text {rod }}$ values.

\section{Conclusion and Discussion}

The subchannel code ATHAS is modified with distributed resistance model to meet the demand of wire wrapped SCWR assembly. Conclusions can be concluded as follows.

(1) The assembly with wire wrap can obtain a more uniform coolant temperature profile than the grid spaced assembly, which will result in a lower peak cladding temperature.

(2) The pressure drop in a wire wrapped assembly is less than that in a grid spaced assembly, which can reduce the operating power of pump effectively.

(3) The wire wrap pitch has significant effect on the flow in the assembly. Smaller $H_{\text {wire }} / D_{\text {rod }}$ will result in stronger cross flow, a more uniform coolant temperature profile, and also a higher pressure drop.

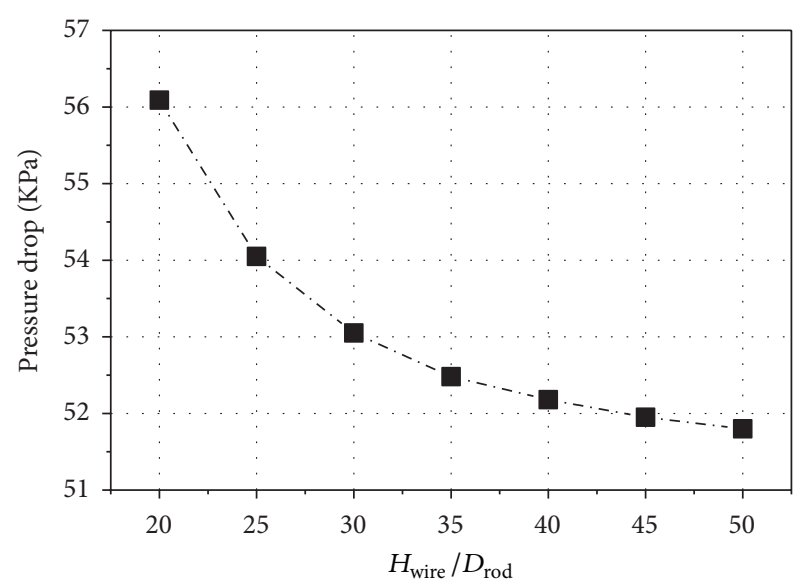

Figure 10: Pressure drop value with different $H_{\text {wire }} / D_{\text {rod }}$.

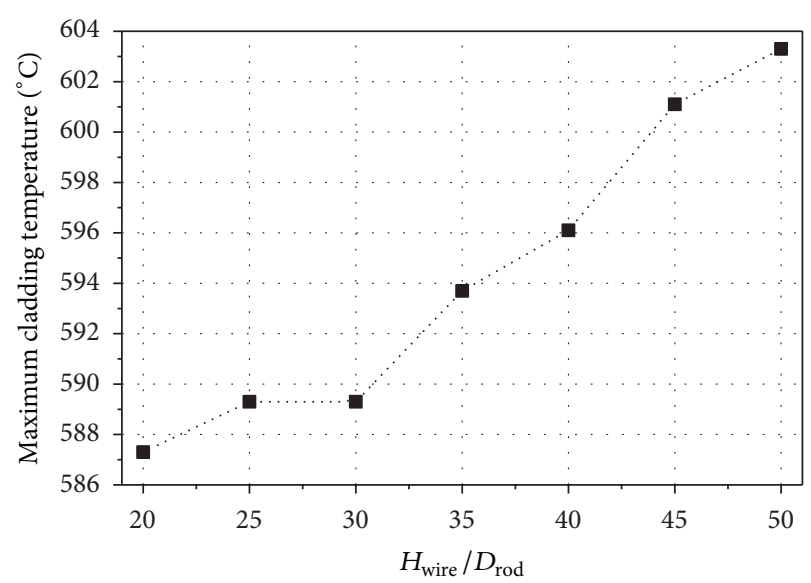

FIGURE 11: The peak cladding temperature comparison with different $H_{\text {wire }} / D_{\text {rod }}$ values.

Although the feasibility of wire wrapped assembly from the thermal-hydraulic point of view is approved in this work, the flow-induced vibration induced by wire wrap still needs further study.

\section{Nomenclature}

$\begin{array}{ll}A: & \text { Area }\left(\mathrm{m}^{2}\right) \\ C_{g}, C_{s}, C_{T}: & \text { Empirical correction factor } \\ D_{e}: & \text { Hydraulic diameter }(\mathrm{m}) \\ f: & \text { Frictional coefficient } \\ g: & \text { Gravity acceleration }\left(\mathrm{m} / \mathrm{s}^{2}\right) \\ h: & \text { Enthalpy }(\mathrm{J} / \mathrm{kg}) \\ h^{\prime}: & \text { Turbulent transport enthalpy }(\mathrm{J} / \mathrm{kg}) \\ H: & \text { Heat transfer coefficient }\left(\mathrm{W} /\left(\mathrm{m}^{2} \cdot \mathrm{K}\right)\right) \\ l: & \text { Lateral pseudo length }(\mathrm{m}) \\ L: & \text { Channel centroid distance }(\mathrm{m}) \\ K: & \text { Frictional coefficient of spacer grid } \\ p: & \text { Pressure }(\mathrm{Pa}) \\ P: & \text { Perimeter }(\mathrm{m}) \\ \mathrm{Pr}: & \text { Prandtl number }\end{array}$


Re: Reynolds number

S: $\quad$ Gap width between rods (m)

$t: \quad$ Temperature $\left({ }^{\circ} \mathrm{C}\right)$

$u: \quad$ Velocity $(\mathrm{m} / \mathrm{s})$

$u^{\prime}: \quad$ Turbulent velocity $(\mathrm{m} / \mathrm{s})$

$V: \quad$ Lateral velocity $(\mathrm{m} / \mathrm{s})$

$W: \quad$ Lateral flow rate $(\mathrm{kg} / \mathrm{s})$

$W^{\prime}$ : Turbulent mixing rate $(\mathrm{kg} / \mathrm{s})$

$\Delta z: \quad$ Axial length $(\mathrm{m})$

$c: \quad$ Mixture velocity $(\mathrm{m} / \mathrm{s})$

$u$ : $\quad$ Mixture axial velocity $(\mathrm{m} / \mathrm{s})$

v: $\quad$ Mixture lateral velocity $(\mathrm{m} / \mathrm{s})$

$A_{R}: \quad$ Rod surface area $\left(\mathrm{m}^{2}\right)$

$A_{W}$ : Wire surface area within a control volume $\left(\mathrm{m}^{2}\right)$

$A_{W}^{\prime \prime}$ : Total wetted surface area including wire spacer $\left(\mathrm{m}^{2}\right)$

$D_{V}: \quad$ Equivalent hydraulic diameter $(\mathrm{m})$

$F_{R}^{A}$ : Axial component of the force exerted by the rod surface $(\mathrm{N})$

$F_{R}^{L}$ : Lateral component of the force exerted by the rod surface $(\mathrm{N})$

$F_{W}^{T}$ : Tangential component of the force exerted by the wire wrap surface $(\mathrm{N})$

$F_{W}^{N}$ : Normal component of the force exerted by the wire wrap surface $(\mathrm{N})$

$S_{T}: \quad$ The rod pitch $(\mathrm{m})$

$S_{L}$ : The distance between two rods in a transverse row $(\mathrm{m})$

$H_{\text {wire }}$ : Wire wrap lead length (m)

$D_{\text {rod }}$ : Fuel rod diameter $(\mathrm{m})$.

\section{Greek Symbols}

$\beta$ : Direction angle, turbulent mixing coefficient

$\phi$ : Fraction of perimeter

$\theta$ : Angle between the channel axis and vertical

$\rho$ : Density $\left(\mathrm{kg} / \mathrm{m}^{2}\right)$

$\alpha$ : The velocity makes an angle from the vertical

$\varphi$ : Wire wrap angle.

\section{Subscripts}

$b$ : Bulk fluid

c: Channel

$i, j$ : Subchannel number

$f$ : Fluid

$k$ : Gap number

$r$ : Rod

$w$ : Conduction wall.

\section{Acronyms}

ATHAS: Advanced thermal-hydraulics analysis subchannel

SCWR: Super critical water-cooled reactor

CANDU: Canada deuterium uranium

RBMK: Reactor of large capacity channel type (in Russian abbreviations)

HPLWR: High performance light water reactor.

\section{Conflict of Interests}

The authors declare that there is no conflict of interests regarding the publication of this paper.

\section{Acknowledgments}

The authors would like to express their appreciation to Atomic Energy of Canada Limited and Xian Jiaotong University for their financial support.

\section{References}

[1] J. Buongiorno, W. Corwin, P. Mac Donald et al., "Supercritical water reactor (SCWR) survey of materials experience and R\&D needs to assess viability," Tech. Rep. INEEL/EXT-03-00693 (Revision 1), Idaho National Engineering Laboratory, Idaho Falls, Idaho, USA, 2003.

[2] R. Duffey, I. Pioro, and H. Khartabil, "Supercritical watercooled pressure channel nuclear reactors: review and status," in Proceedings of the GLOBAL, Tsukuba, Japan, October 2005.

[3] A. Otsubo, T. Okada, N. Takahashi, K. Sato, and N. Hattori, "Occurrence of wear marks on fast reactor fuel pin cladding," Journal of Nuclear Science and Technology, vol. 36, no. 6, pp. 522534, 1999.

[4] X. Cheng and U. Müller, "Critical heat flux and turbulent mixing in hexagonal tight rod bundles," International Journal of Multiphase Flow, vol. 24, no. 8, pp. 1245-1263, 1998.

[5] K. Fischer, T. Schulenberg, and E. Laurien, "Design of a supercritical water-cooled reactor with a three-pass core arrangement," Nuclear Engineering and Design, vol. 239, no. 4, pp. 800 $812,2009$.

[6] J. Buongiorno and P. MacDonald, "Supercritical water reactor (SCWR). Progress Report for the FY-03 Generation IV R\&D activities for the development of the SCWR in the U.S.", Tech. Rep. INEEL/EXT-03-01210, Idaho National Engineering and Environmental Laboratory, 2003.

[7] S. Himmel, A. G. Class, E. Laurien, and T. Schulenberg, "Determination of mixing coefficients in a wire-wrapped HPLWR fuel assembly using CFD," in Proceedings of the International Conference on Advances in Nuclear Power Plants (ICAPP '08), pp. 670-679, Anaheim, Calif, USA, June 2008, P.8053.

[8] E. Laurien, H. J. Wang, Y. Zhu, and H. Z. Li, "Flow and heat transfer of a heated rod with a wrapped wire inside a channel," in Proceedings of the 4th International Symposium on Supercritical Water-Cooled Reactors, Heidelberg, Germany, March 2009, paper no. 29.

[9] L. Chandra, J. L. Nijeholt, D. C. Visser, and F. Roelofs, "CFD analyses on the influence of wire wrap spacers on heat transfer at supercritical conditions," in Proceedings of the 4th International Symposium on Supercritical Water-Cooled Reactors, Heidelberg, Germany, March 2009, paper no. 30.

[10] J. Q. Shan, B. Zhang, C. Y. Li, and L. K. H. Leung, "SCWR subchannel code ATHAS development and CANDU-SCWR analysis," Nuclear Engineering and Design, vol. 239, no. 10, pp. 1979-1987, 2009.

[11] I. L. Pioro, R. B. Duffey, and T. J. Dumouchel, "Hydraulic resistance of fluids flowing in channels at supercritical pressures (survey)," Nuclear Engineering and Design, vol. 231, no. 2, pp. 187-197, 2004. 
[12] I. L. Pioro, H. F. Khartabil, and R. B. Duffey, "Heat transfer to supercritical fluids flowing in channels-empirical correlations (survey)," Nuclear Engineering and Design, vol. 230, no. 1-3, pp. 69-91, 2004.

[13] H.-Y. Jeong, K.-S. Ha, Y.-M. Kwon, Y.-B. Lee, and D. Hahn, “A dominant geometrical parameter affecting the turbulent mixing rate in rod bundles," International Journal of Heat and Mass Transfer, vol. 50, no. 5-6, pp. 908-918, 2007.

[14] J. Q. Shan, L. Leung, J. Yang et al., "Subchannel code development for supercritical water-cooled reactor," in Proceedings of the 4th International Symposium on Supercritical Water-Cooled Reactors, Heidelberg, Germany, March 2009.

[15] C. Y. Li, Subchannel analysis of supercritical water reactor [M.S. thesis], Xian Jiaotong University, 2008.

[16] C. Y. Li, J. Q. Shan, and L. K. H. Leung, "Subchannel analysis of CANDU-SCWR fuel," Progress in Nuclear Energy, vol. 51, no. 8, pp. 799-804, 2009.

[17] H. Ninokata, A. Efthimiadis, and N. E. Todreas, "Distributed resistance modeling of wire-wrapped rod bundles," Nuclear Engineering and Design, vol. 104, no. 1, pp. 93-102, 1987.

[18] T. Schulenberg, J. Starflinger, and J. Heinecke, “Three pass core design proposal for a high performance light water reactor," in Proceedings of the 2nd International Conference on Innovative Nuclear Energy Systems (COE-INES '06), Yokohama, Japan, November 2006.

[19] C. L. Waata, Coupled Neutronics/Thermal-Hydraulics Analysis of a High-Performance Light-Water Reactor Fuel Assembly, vol. 7233 of FZKA, Forschungszentrums Karlsruhe, Karlsruhe, Germany, 2005.

[20] X. Cheng, T. Schulenberg, D. Bittermann, and P. Rau, "Design analysis of core assemblies for supercritical pressure conditions," Nuclear Engineering and Design, vol. 223, no. 3, pp. 279294, 2003.

[21] P. R. Diller, Wire wrapped fuel pin hexagonal arrays for PWR service [Ph.D. thesis], Massachusetts Institute of Technology, 2005. 


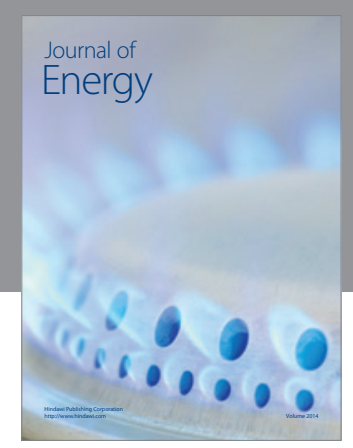

Journal of

Industrial Engineering
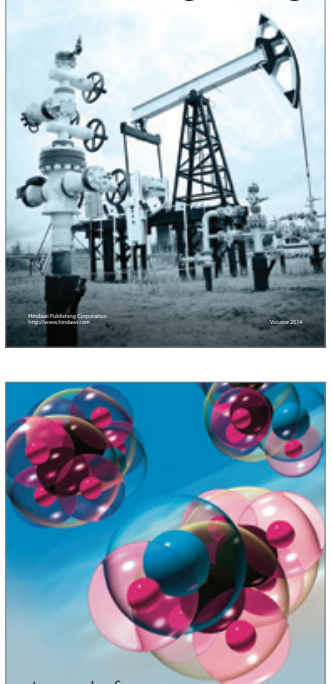

Fuels
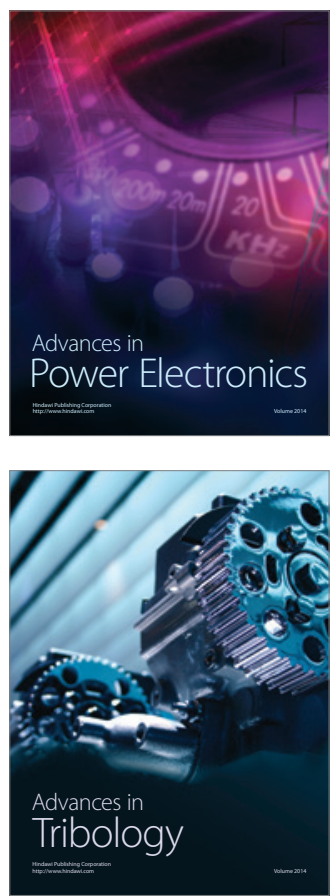

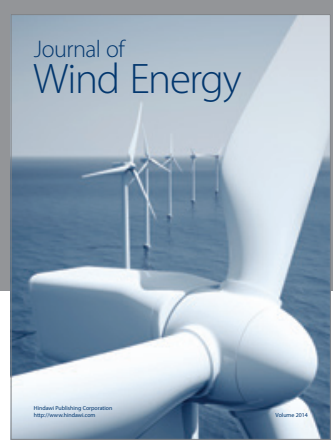

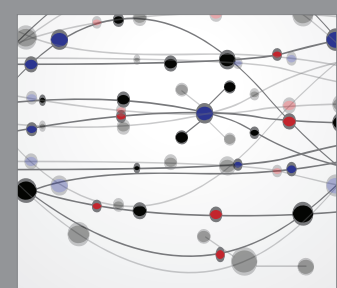

The Scientific World Journal

Submit your manuscripts at http://www.hindawi.com

Journal of

Structures
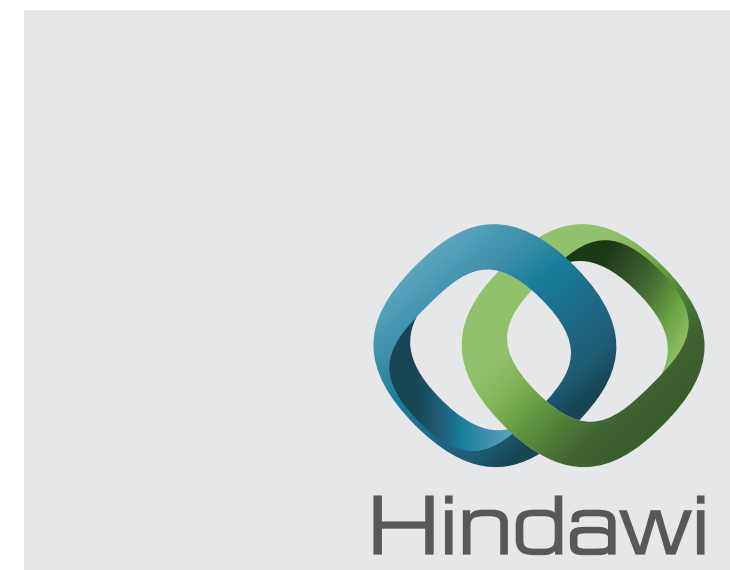

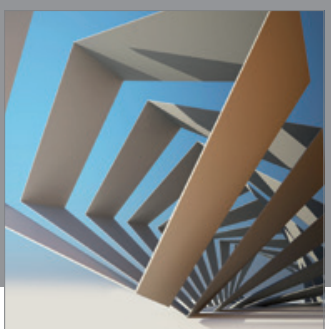

Rotating

Machinery
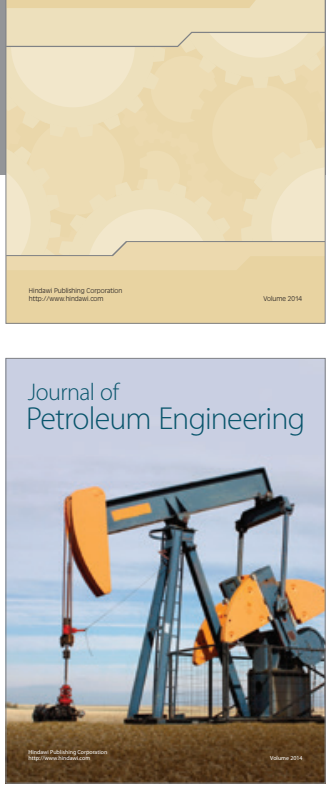

Journal of

Solar Energy
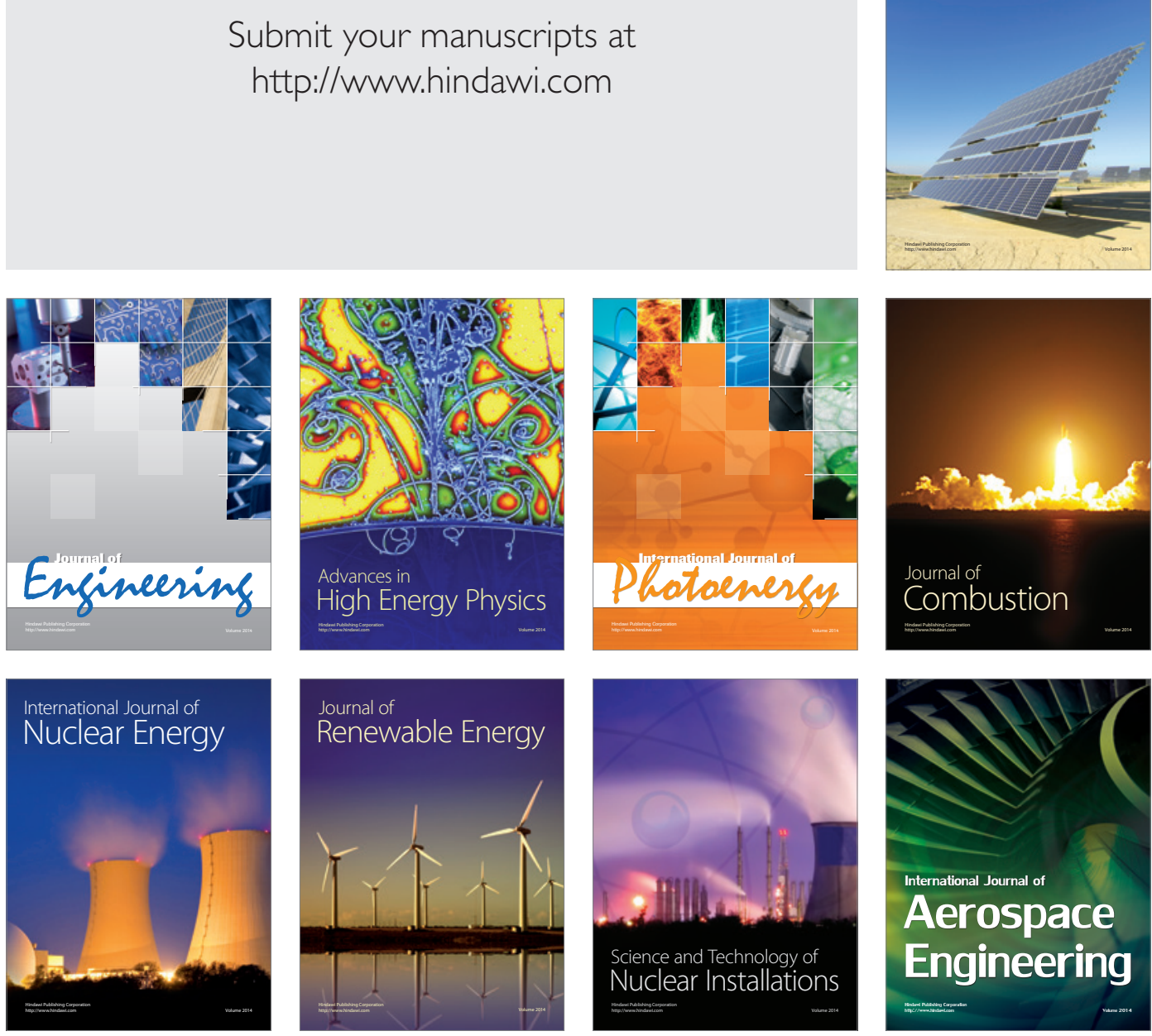